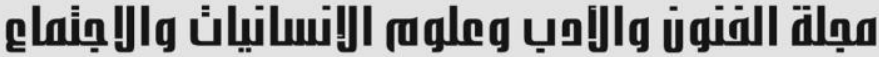

Journal of Arts, Literature, Humanities and Social Sciences

\section{الاداء التدريسي لمعلمي الرياضيات وعلاقته بمهارات التواصل الرياضي لإيهي الريات}

م.د. سلوى محسن حمد المد المد المديريـة العامة لتربية بغداد /الكرخ الثانية ـ وزارة التربية ــ العراق

يهدف البحث الحالي الى التعرف على الاداء التذريس لمعلمي الرياضيات وعلاقتها بمهار ات التو اصل الرياضي

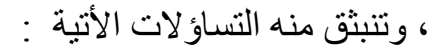

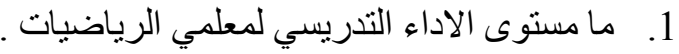
2. ما مستوى مهار ات التو اصل الرياضي لمعلمي الرياضيات. 3. ما طبيعة العلاقة الارتباطية بين الاداء التدريسي و مهار ات التو اصل الرياضي لمعلمي الرياضيات. اتبعت الباحثة منهج البحث الوصفي ، وبلغت عينة البحث (60) معلم ومعلمة من معلمي الرياضيات في المديرية العامة لتربية بغداد الكرخ /2 ، ولتحقيق اهداف البحث وفرضياته تطلب ذلك بناء بطاقة ملاحظة للإداء التدريسي ، وبطاقة ملاحظة لمهار ات التواصل الرياضي ، وتم ايجاد الصدق و الثبات لأداتي البحث ، وطئ وطبقت

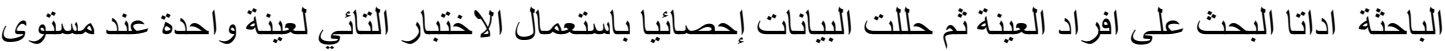
الدلالة (0.05).

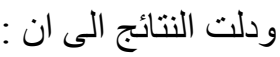
1. وجود دلالة احصائية عند مستوى الدلالة (0.05) للفرق بين المتوسط الحسابي والمتوسط الفرضي في الاداء التدريسي، ولصالح المتوسط الفرضي. 2. وجود دلالة احصائية عند مستوى الدلالة (0.05) للفرق بين المتوسط الحسابي والمتوسط الفرضي في

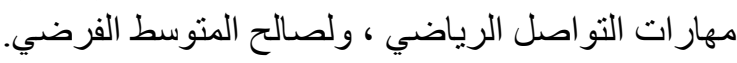
3. وجود علاقة ارتباطية متوسطة بين الاداء التدريسي لمعلمي الرياضيات ، وبين مهار ات التو اصل الرياضي لديهم. الكلمات المفتاحية: الاداء التدريسي، معلمي الرياضيات، مهار ات التو اصل الرياضي. 


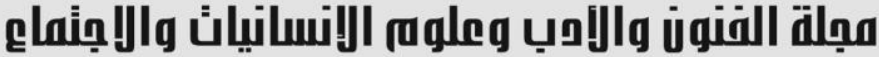 \\ Journal of Arts, Literature, Humanities and Social Sciences \\ www.jalhss.com \\ Volume (55) August 2020 \\ العدد (55) أغسطس 2020
}

\section{Teaching Performance of Mathematics Teachers and Their Relationship to Mathematical Communication Skills}

\author{
Dr. Salwa Mohsen Hamad \\ Directorate General of Education Baghdad / Karkh2 \\ Ministry of Education - Iraq
}

\section{ABSTRACT}

The current research aims to identify the teaching performance of mathematics teachers and their relationship to mathematical communication skills, and the following questions arise from it:

1. What is the level of teaching performance of mathematics teachers?

2. What is the level of mathematical communication skills for mathematics teachers?

3. What is the nature of the correlation between teaching performance and mathematical communication skills for mathematics teachers?

The researcher followed the descriptive research approach, and the research sample reached (60) male and female teachers of mathematics teachers at the General Directorate of Education, Baghdad Al-Karkh / 2, and to achieve the goals and hypotheses of the research, this required building a note card for teaching performance, and a note card for mathematical communication skills, and honesty and consistency were found for the research tools And the researcher applied the research tools to the sample members, and then analyzed the data statistically by using the Ttest for one sample at the level of significance (0.05)

The results indicated that:

1. There is a statistical significance at the level of significance $(0.05)$ for the difference between the arithmetic mean and the hypothetical mean in the teaching performance, and in favor of the hypothetical average.

2. There is a statistical significance at the level of significance $(0.05)$ for the difference between the arithmetic average and the hypothetical mean in mathematical communication skills, and for the benefit of the hypothetical average.

3. There is an intermediate correlation between the performance of the teachers of mathematics and their mathematical communication skills.

Keywords: teaching performance, mathematics teachers, mathematical communication skills. 


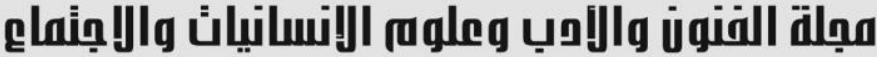

Journal of Arts, Literature, Humanities and Social Sciences
www.jalhss.com
Volume (55) August 2020
2020 (55) أغسطس

مشكلة البحث : يعد المعلم عنصر هام من عناصر نهضية المجتمع وتقدمه ،وهو هور حجر الزاوية المهم في العملية

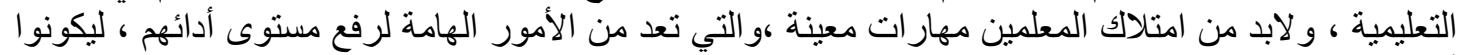

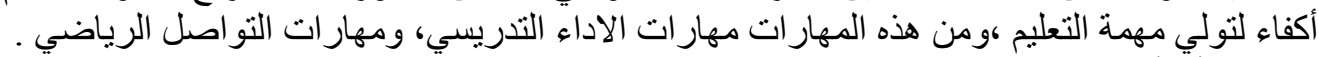

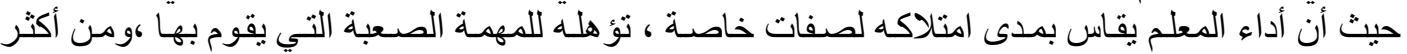

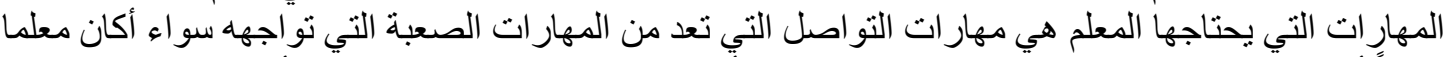

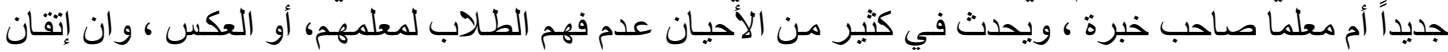

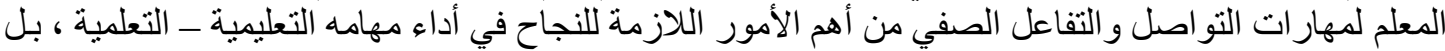

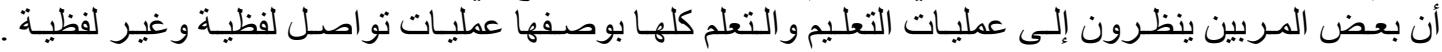

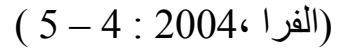

ويرى (بدوي ،2003) أن لمهار ات التواصل الرياضي دور ا مهما في مساعدة التلاميذ على تكوين ارتباطسات

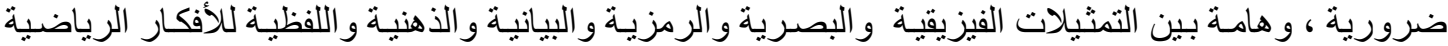

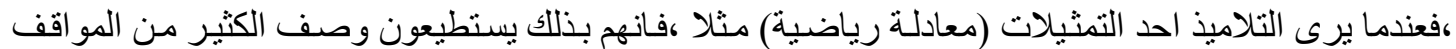

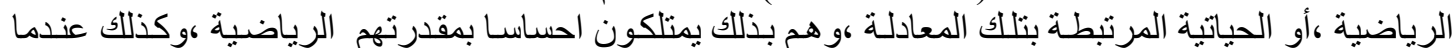

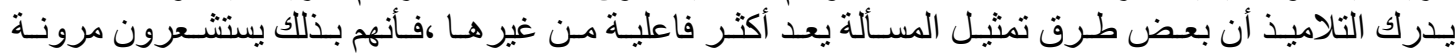

$$
\text { (بدوي، 2003، 272) }
$$

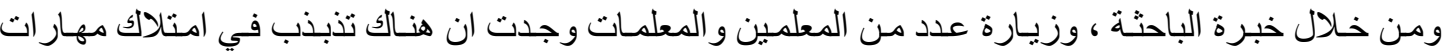

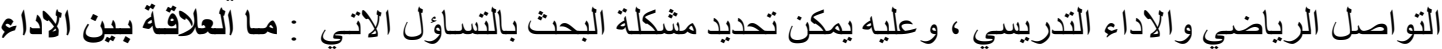

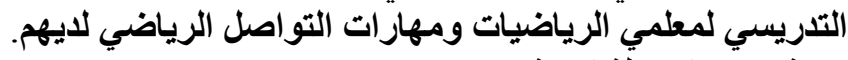

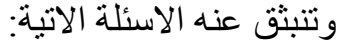

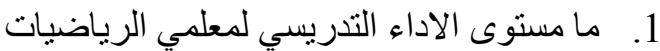
2.

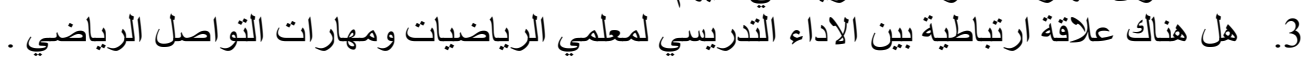

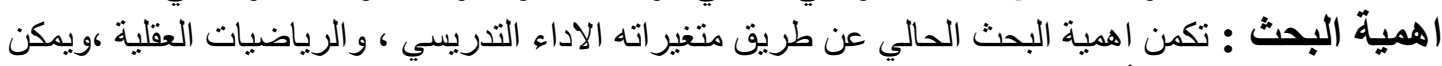
توضيحها من خلال ما يأتي : 1. رفد الميدان التربوي ببطاقة ملاحظة للاداء التدريسي لمعلمي الرياضيات ، وبطاقة ملاحظة لمهارات

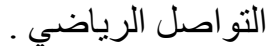

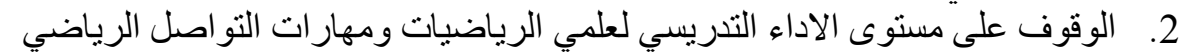

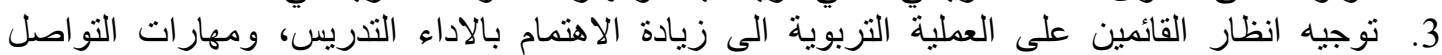
الرياضي لمعلمي الرياضيات. اهداف البحث: : يهدف البحث الحالي الى التعرف على الإنى الاداء التدريس لمعلمي الرياضيات و علاقتها بمهار ات

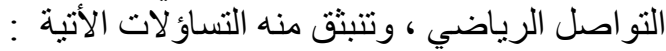

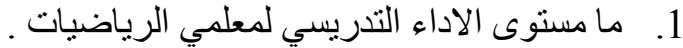
2.

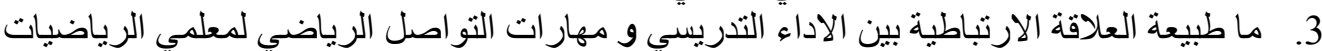

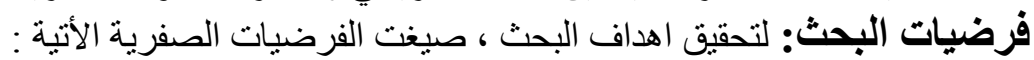
1. لا يوجد فرق ذو دلالة إحصائية عند مستوى الدلالة (0.05) بين متوسطي درجات معلمي عينة البحث

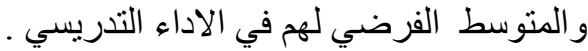

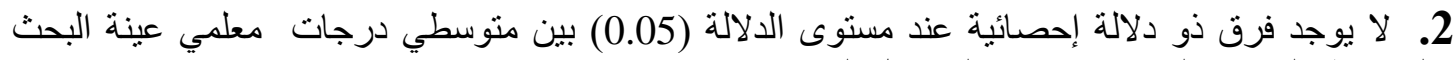

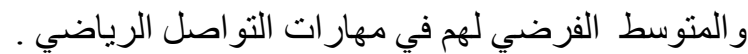
3. لا توجد علاقة ارتباطية عند مستوى الدلالة (0.05) بين الاداء التدريسي لمعلمي الرياضيات ، ومهار ات

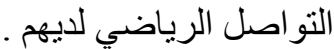




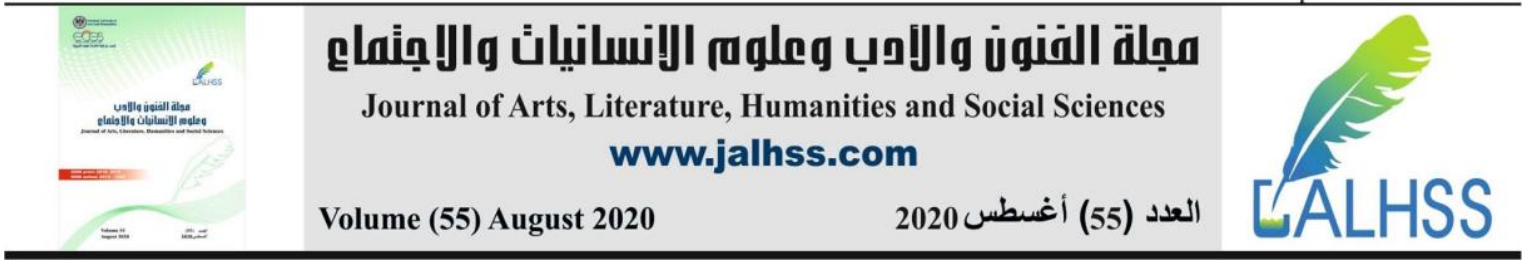

تحديد المصطلحات: فيما يأتي تحديد لمعاني المصطلحات التي وردت في منن هذا البحث مع التعريف الاجر ائي و النظري لكل منها : المائ

Instructional Performance الاداء التدريس التئ 1. عرفه ( المفتي، 1982 ) بأنه :-" سلوك المعلم بجميع أفعاله المتعلقة بالعملية التعليمية داخل الصف وخارجه

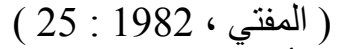

2. عرفه ( الجنابي ، 2002 ) بأنه :- "عملية قياس وتحديد مدى مـايؤديـه المعلم في الموقف التعليمي داخل الصف وخلال مدة زمنية محددة "

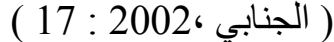

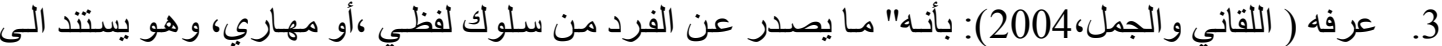

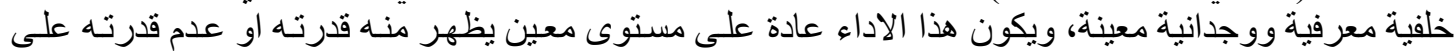

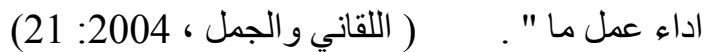

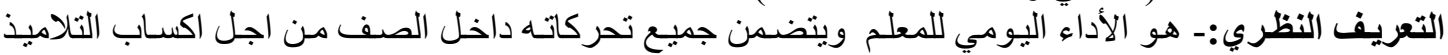

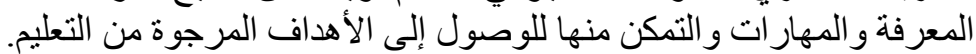

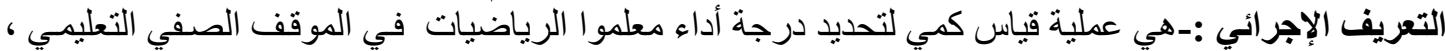

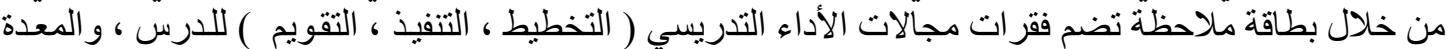

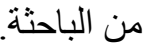

التواصل الرياضي Mathematical Communication:

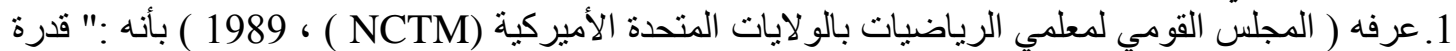

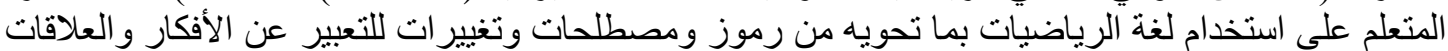

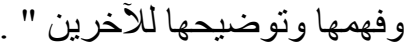
(NCTM, $1989: 214)$

2. عرفه ( بدوي، 2003 ) بأنه: " تبادل الأفكار أو المعلومات أو الآراء الرياضية بين المدرس وطلبته والطلبة

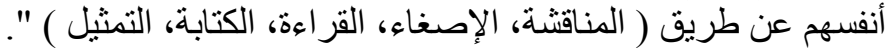

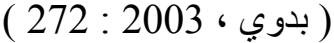

التعريف النظري:- قدرة معلم الرياضيات على استخدام لغة الرياضيات في شرح مـادة الرياضيات و ايصـالها

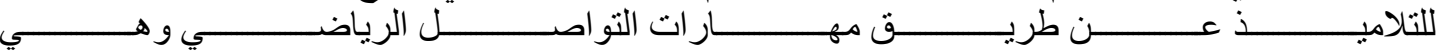

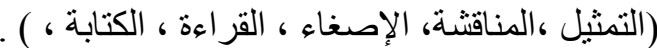

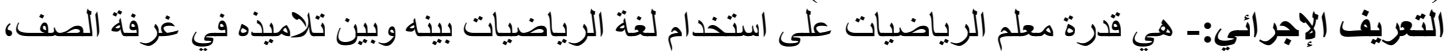

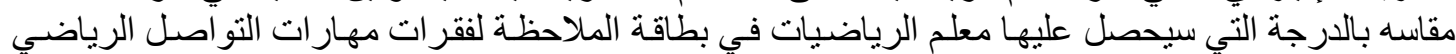
وهي(التمثيل ، المناقثنة، الإصغاء، القر اءة، الكتابة ) المعدة من الباحثة.

خلفية نظرية الاداء التدريسي تلفيه

اهداف تقويم الآداء التّريسي :ان من اهداف تقويم الاداء التدريسي ما يأتي :

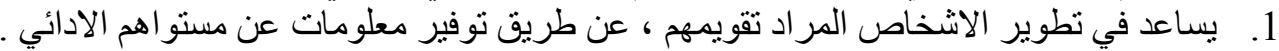

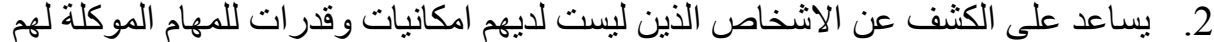

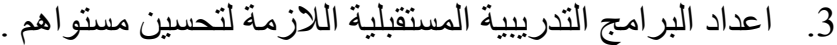
4. اشعار العاملين بالمسؤولية الملقاة عليهم ، ليبذلوا جهدهم في تطوير مستوياتهم . 


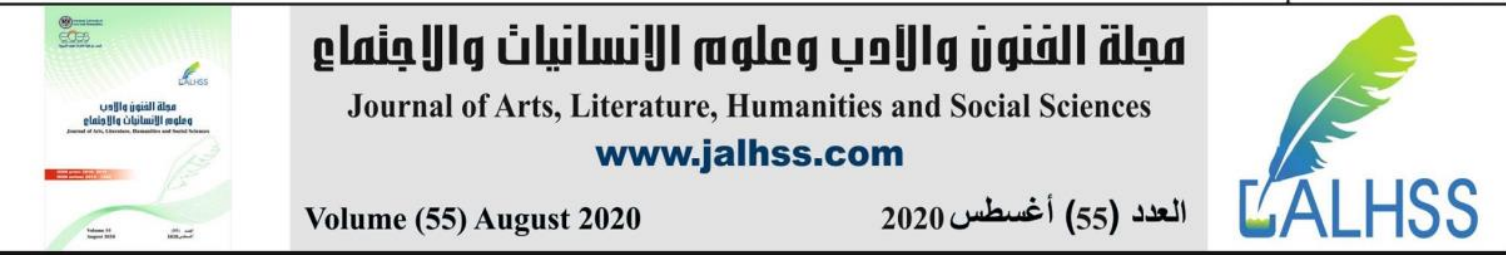

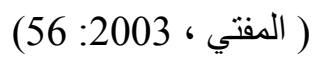

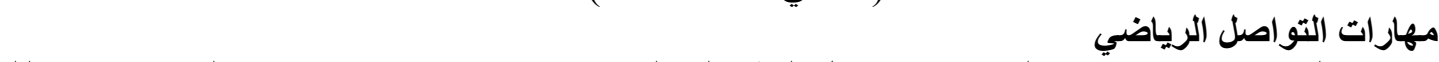

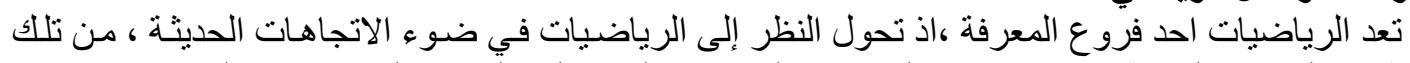

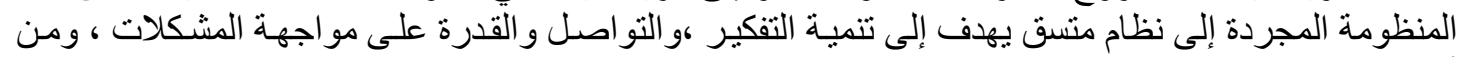

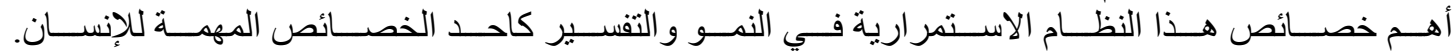

( Thompson .L , 2007:3-5 )

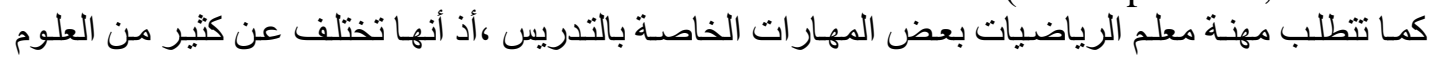

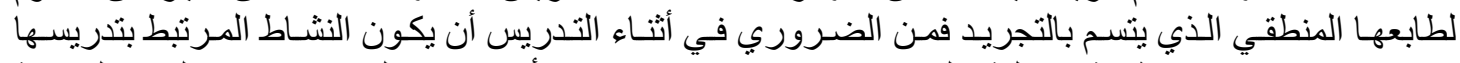

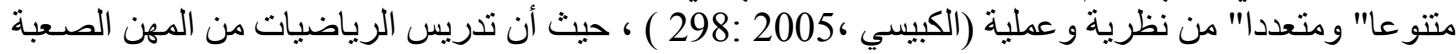

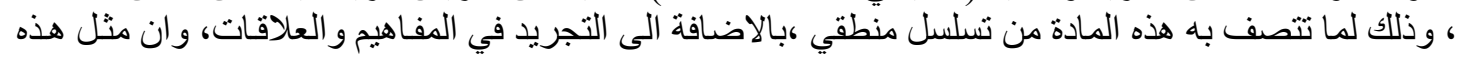

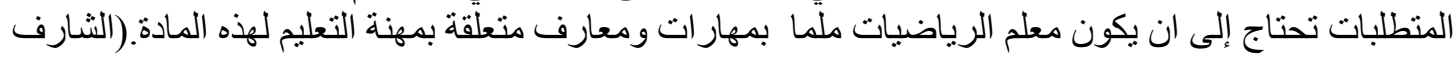

(5: 1996،

و اكد( الفرا ،2004 ) ان كفاءة المعلم تقاس بامتلاكه لكفايات ادائية ،ومهنبة متنو عة وصفات التهات خاصة تؤه هله

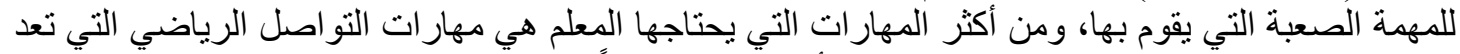

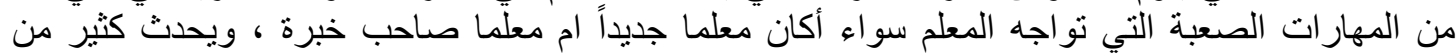

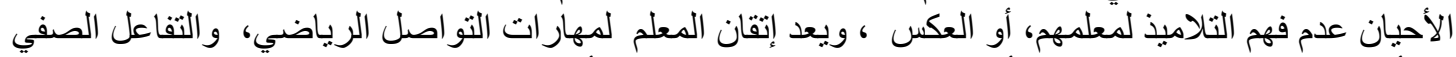

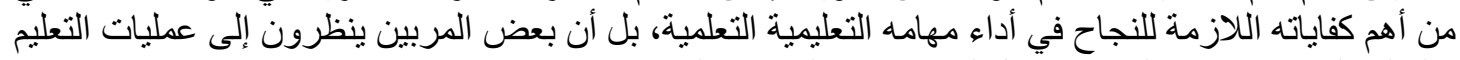

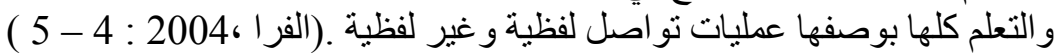

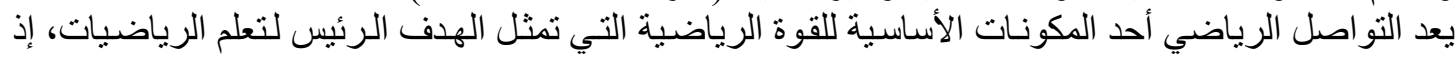

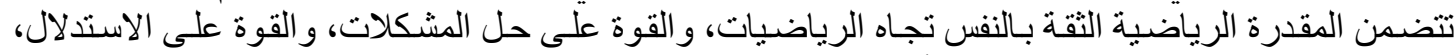
و التو اصل الرياضي مع الآخرين حول الأفكار و الحلول. (Cantlon (1998: 109).

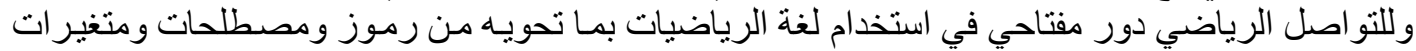

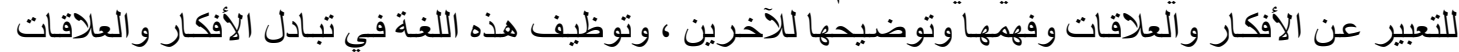

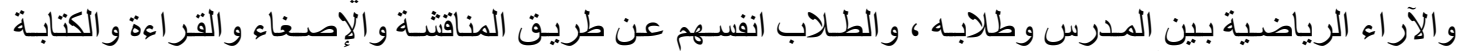

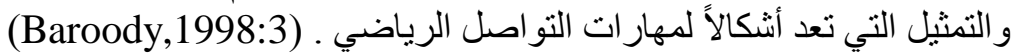

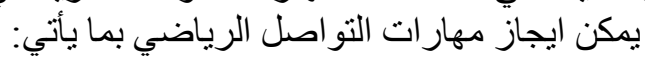

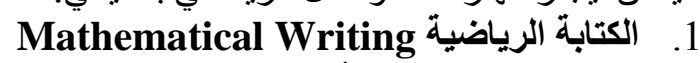

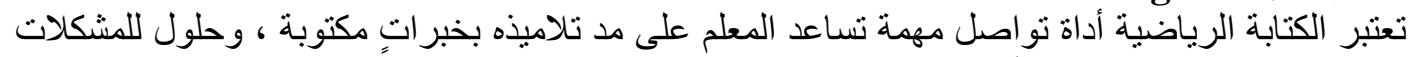

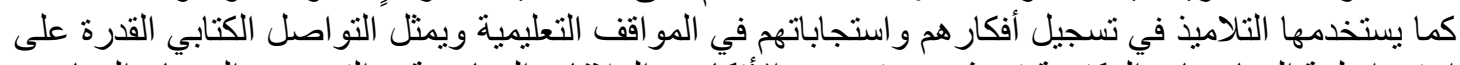

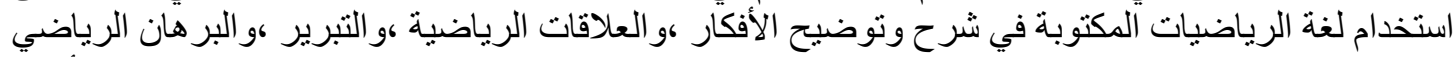

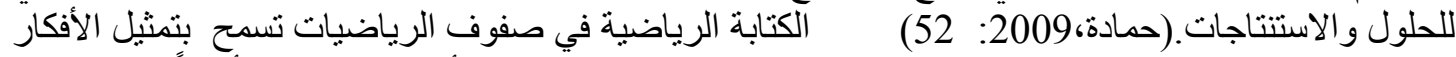

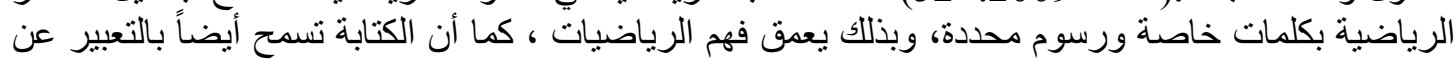

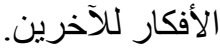
و ون خصائص التورين اصل الكل الكتابي( الكتابة الرياضية) ما يأتي: -

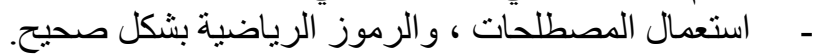

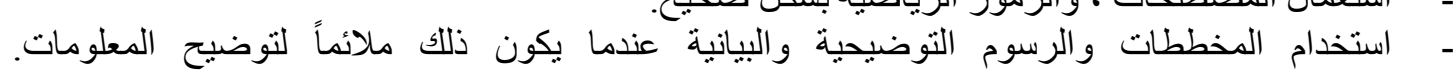
(بدوي، 150:2007)

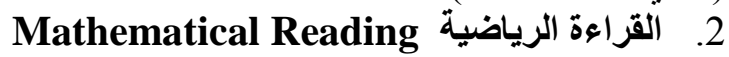

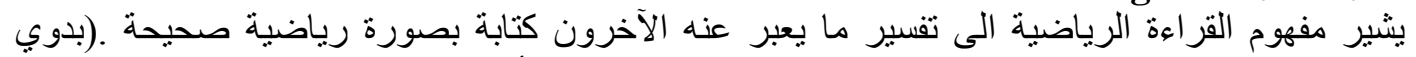

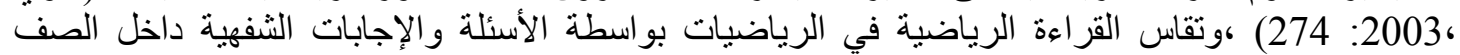

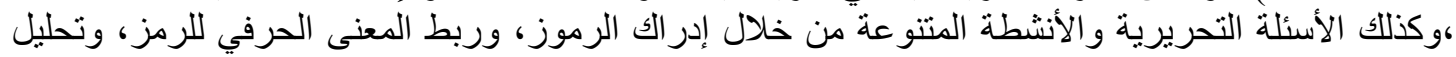
العلاقات بين الرموز ،وحل المسائل اللفظية بل بل ، 1986 : 244 ) 


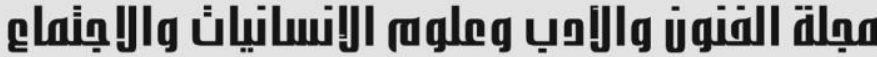

Journal of Arts, Literature, Humanities and Social Sciences
www.jalhss.com
Volume (55) August $2020 \quad 2020$ العدد (55) أغطس 20

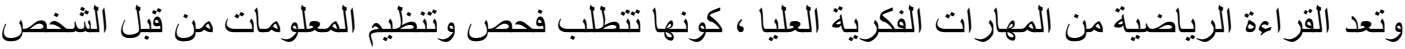

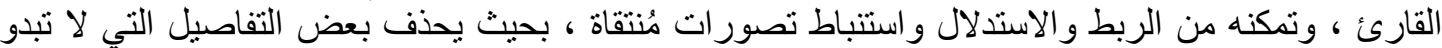

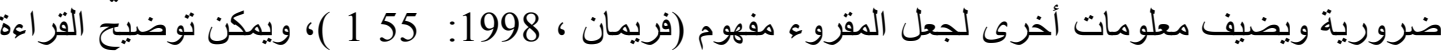
الرياضية بما يأتي : الفيفة 1 1. القرة على فهم واستخدام اللغة الرياضية المكتوبة.

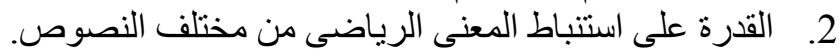

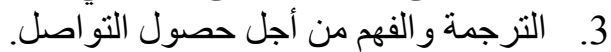

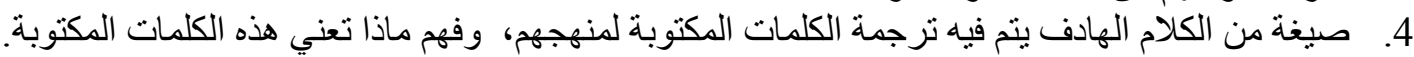

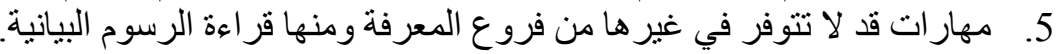

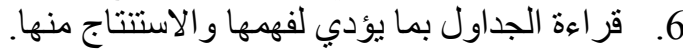

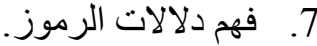

8. استيعاب معطيات المعادلات الرياضية.

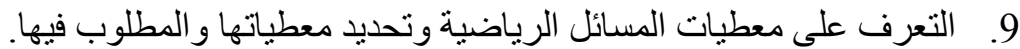

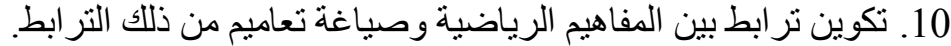

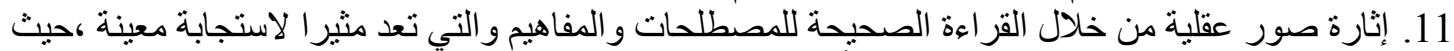

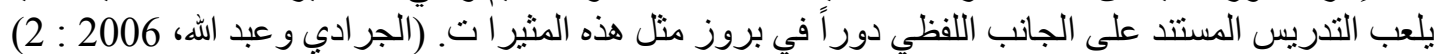

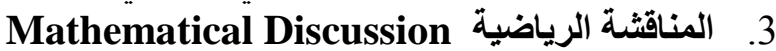

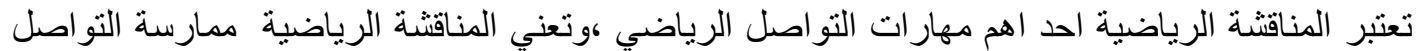

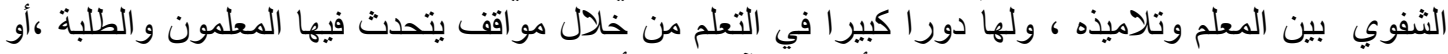

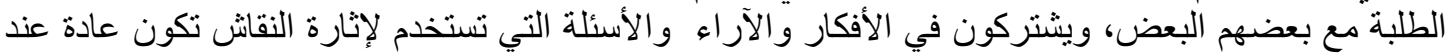

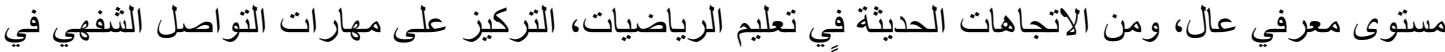

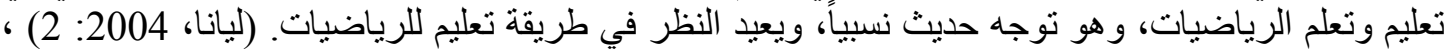

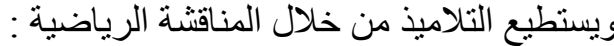

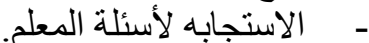

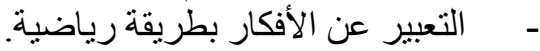

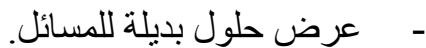

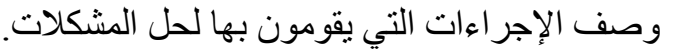

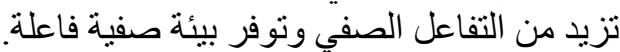
تتمي لديهم القدرة على تبادل الأفكار و الإفادة من أفكار ذوبة ذوي القدرات العالية من الطلبة (Morgan, 1999:212 )

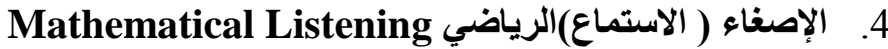

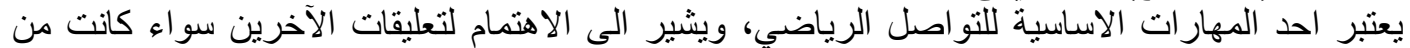

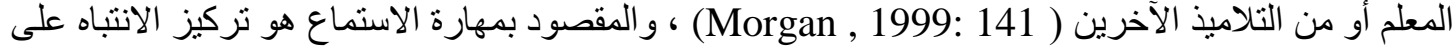

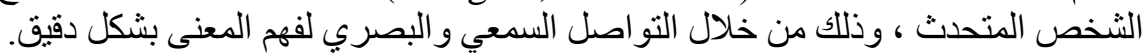

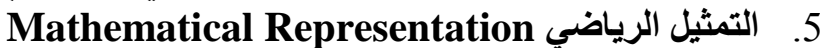

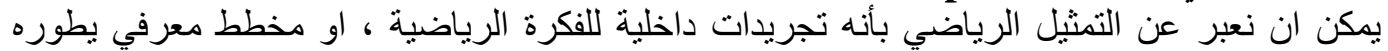

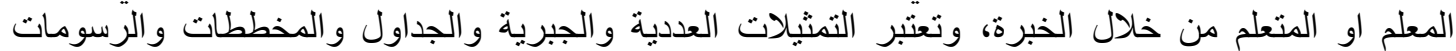

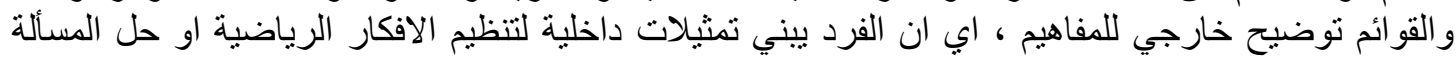

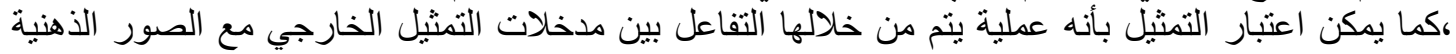

(Pape \& Tchoshanov,2001:118 )

$$
\text { ويمكن توضيح مهارة التمثيل الرياضي بما يأتي : }
$$




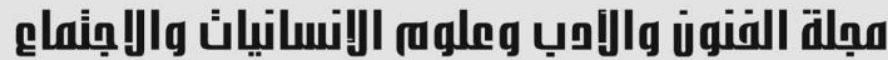

Journal of Arts, Literature, Humanities and Social Sciences www.jalhss.com

- ترجمة المسألة او الفكرة الرياضية الى صيغة جديدة (شكل توضيحي ، او جدول للمعلومات ، او شكل بياني

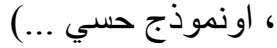

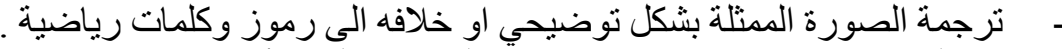

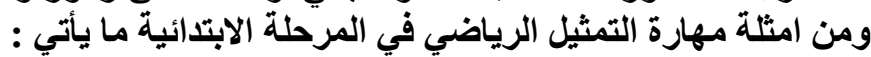

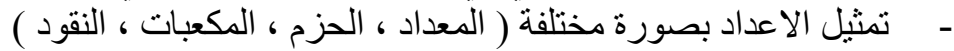

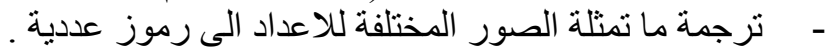

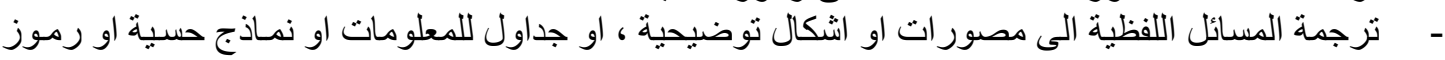
ومعادلات جبرية .

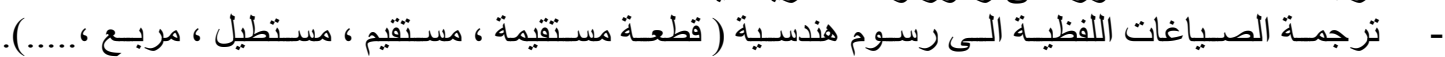

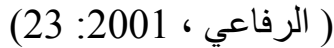

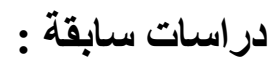

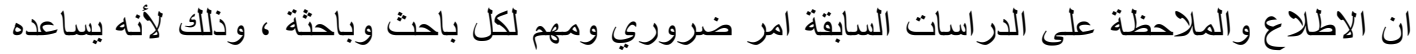

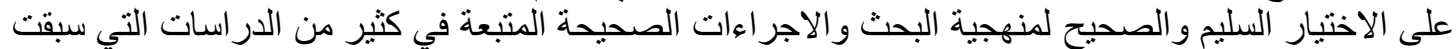
در استه، كما يساعده الاطلاع على الادوات و الاجر اءات و الاختبار الات التات التى اتباع الخطو ات الصحيحة في بحثه ،

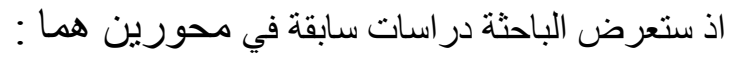

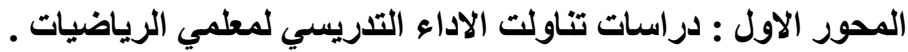

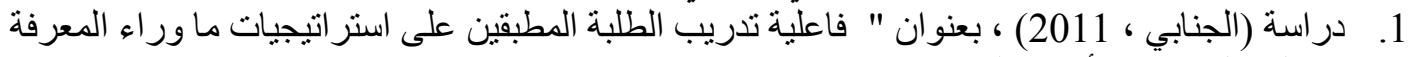

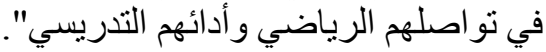

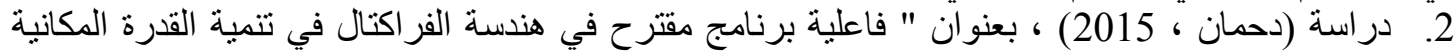

\begin{tabular}{|c|c|c|c|c|c|c|c|}
\hline نتائج الدراسة & 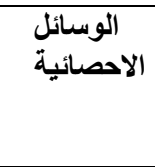 & الدراسة الدوات & وجنم & رحلة الاراسية & منهج & & والباحثة \\
\hline 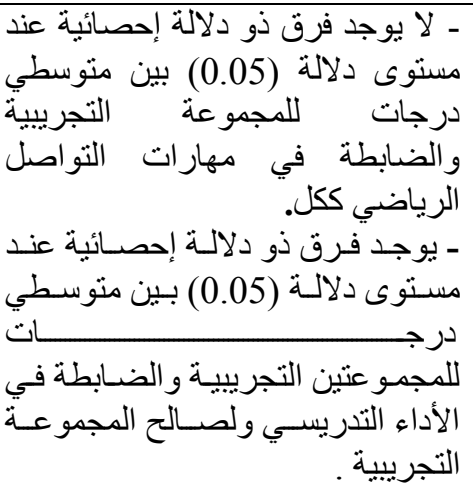 & 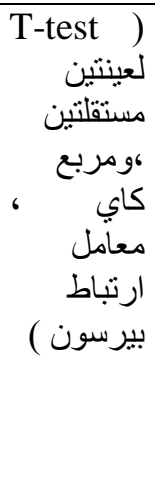 & مناقتية & وطالب & 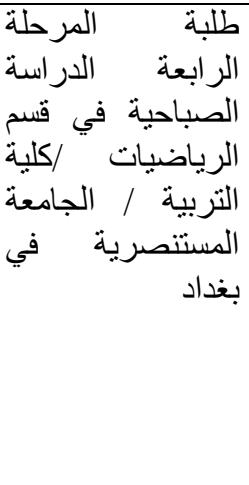 & التجريبي & 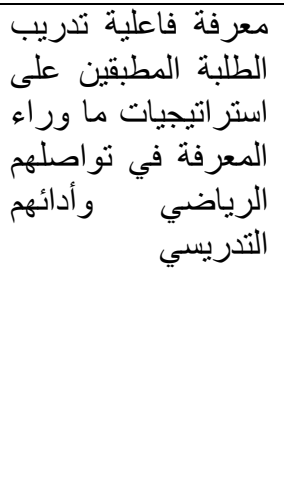 & الجنابي \\
\hline 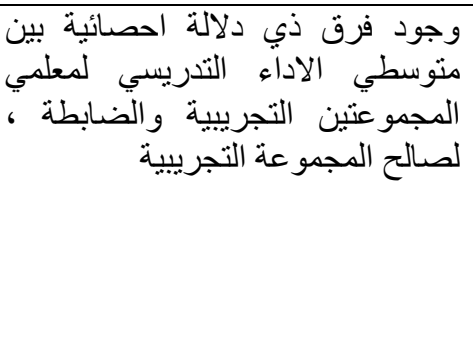 & التباين & القياسبار & معلما 130 ) & للمرحلة الاسلياتية & التجريبي & 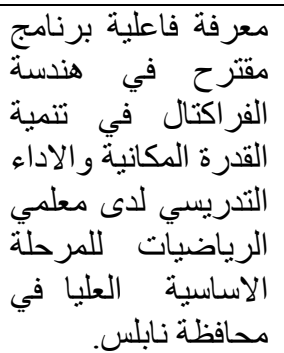 & $\begin{array}{l}\text { دحمان } 2015 \\
\text { نابلس }\end{array}$ \\
\hline
\end{tabular}




\begin{tabular}{|c|c|c|c|c|c|c|c|}
\hline \multirow{2}{*}{ 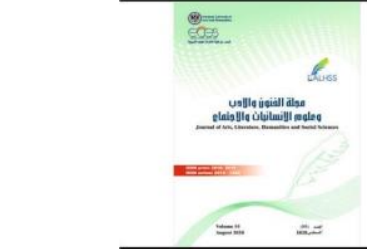 } & \multicolumn{5}{|c|}{ 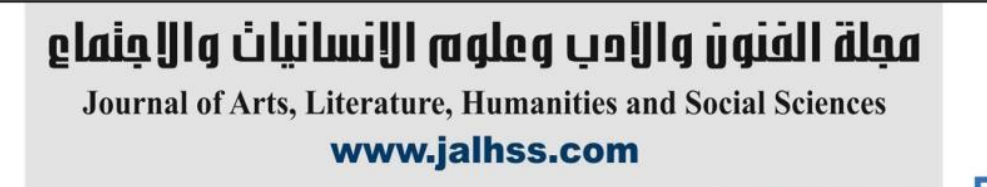 } & \multirow{2}{*}{ HSS } & \multirow[b]{3}{*}{ والباحثة } \\
\hline & \multicolumn{2}{|c|}{ Volume (55) August 2020} & \multicolumn{3}{|c|}{ العدد (55) أغسطس 2020} & & \\
\hline نتائج الدراسة & الاحصائية الوسائل & الداسة & وجنم & المرحلة الاراسية & الدراسة & راسة & \\
\hline 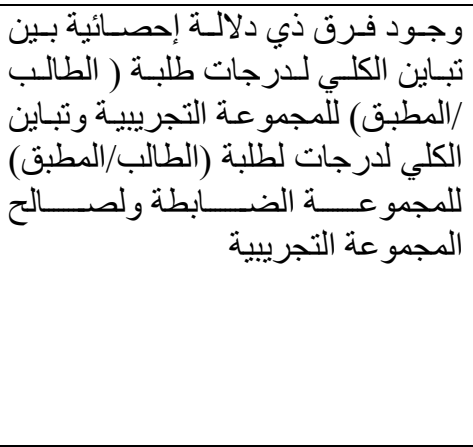 & معرين، & 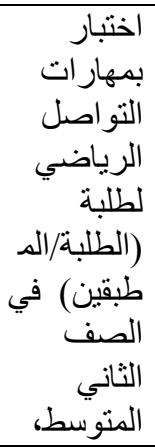 & وطل & 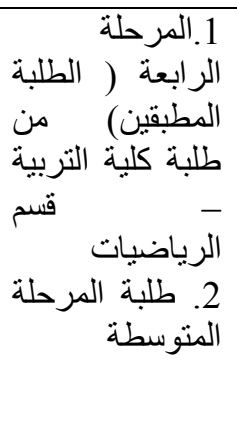 & التجريبي & 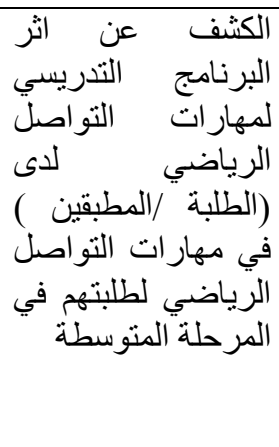 & العر ال 2009 \\
\hline 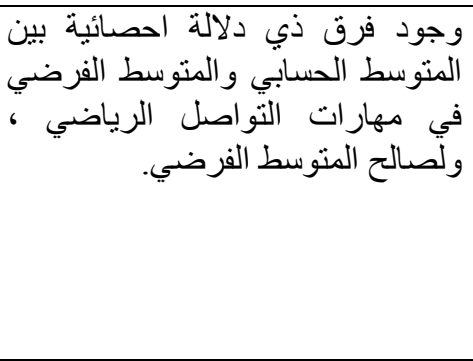 & 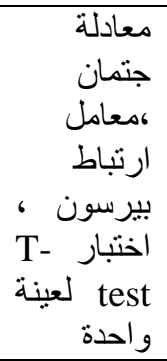 & 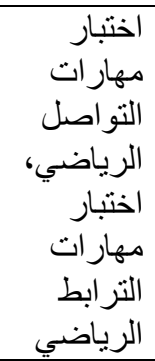 & 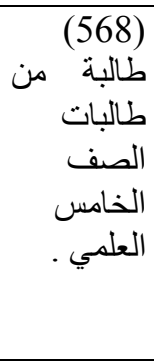 & طالبات الخامس & الوصنهي & 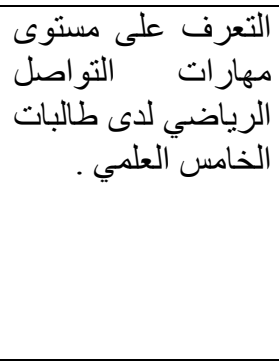 & العراق 2013 \\
\hline
\end{tabular}

منهج البحث: اعتمدت الباحثة منهج البحث الوصفي لتحقيق اهداف البحث ، وذلك لملاعمة هذا المنهج لأهداف

مجتمع البحث: شكل المجتمع معلمي ومعلمات الرياضيات في المدارس الابتدائية في المديرية العامة لتربية

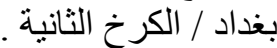
عينة البحث: تم اختبار عينة البحث بشكل عشوائي من مجتمع البحث، والبالغ عددهم ( 60) معلم ومعلمة اختصاص رياضيات ، وخريجي معهد اعداد المعلمين. اداتا البحث: : البه: اولا : بطاقة ملاحظة الاداء التدريس .

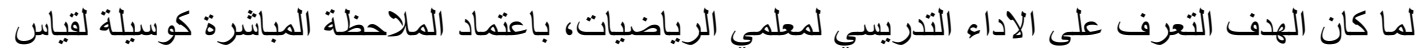

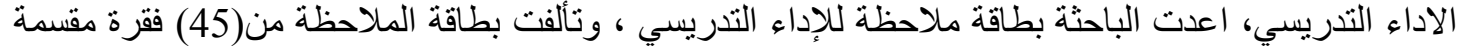

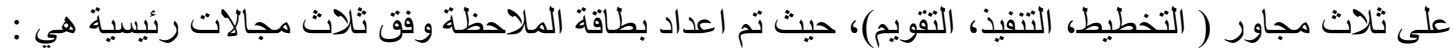

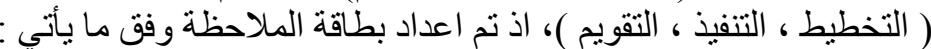

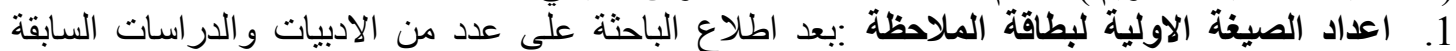

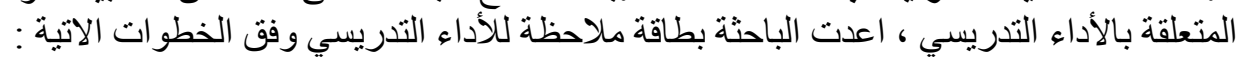
أ. تحديد الهدف من بطاقة الملاحظة :تهدف بطاقة الملاحظة اللى تحديد درجة الاداء التندريسي لمعلمي

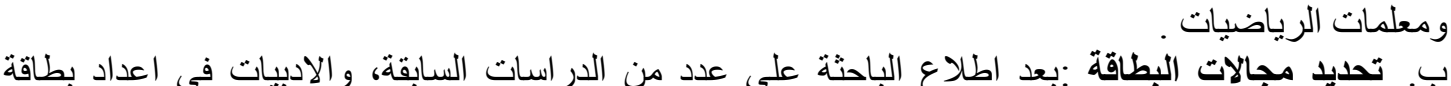

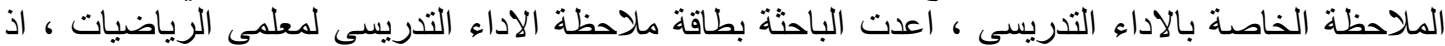

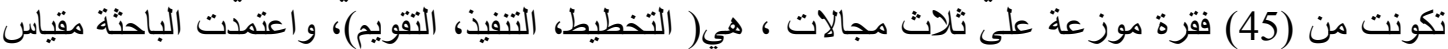

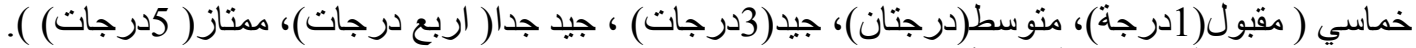

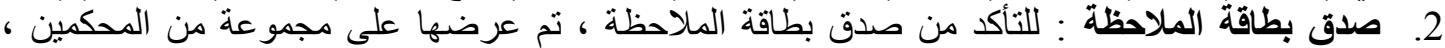
لغرض بيان أر اءهم في صلاحية فقرات بطاقة الملاحظة ، حيث تم اجر اء بعض التعديلات على فقر ات البطاقة ، 


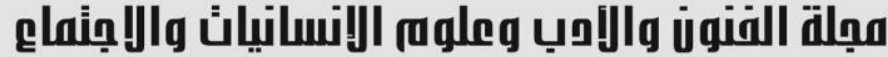

Journal of Arts, Literature, Humanities and Social Sciences www.jalhss.com

كما تم حذف عدد من الفقرات، وقذ اصبح عدد الفقرات (41) فقرة ، موزعة على ثلاث مجالات ، واعتمدت

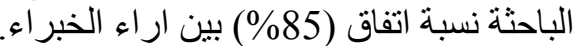

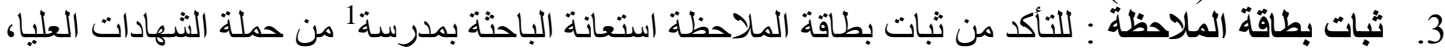

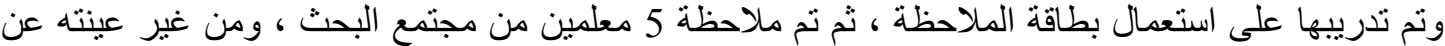

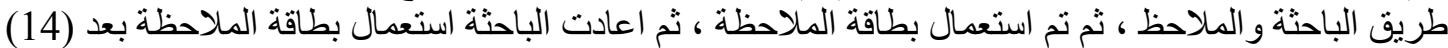

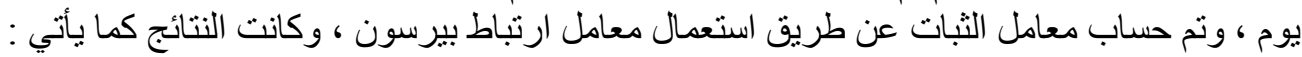

\begin{tabular}{|c|c|c|}
\hline درجة الثبات & نوع الثبات & ت \\
\hline 0.92 & الباحثة مع نفسها & 1 \\
\hline 0.85 & الباحثة مع الملاحظ & 2 \\
\hline
\end{tabular}

وان قيم معامل الارتباط في الجدول اعلاه تدل على ثبات بطاقة الملاحظة .

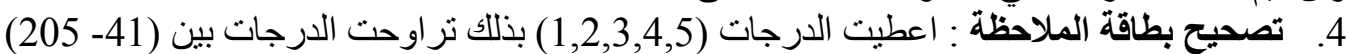

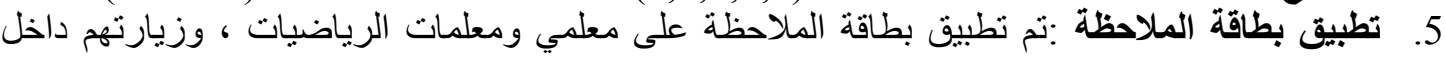
الصفوف .

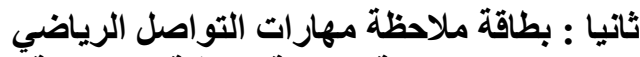
1. (التمثيل ،المناقثة ،الإصغاء، القراءة الاءة ،الكتابة).

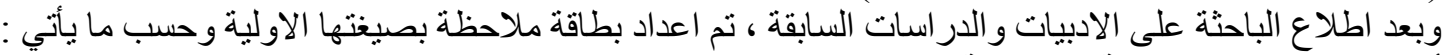
أ.تحديد الهدف من بطاقة الملاحظة :تهدف بطاقة الملاحظة الى تحديد درجة معلمي ومعلمات الرياضيات

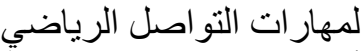

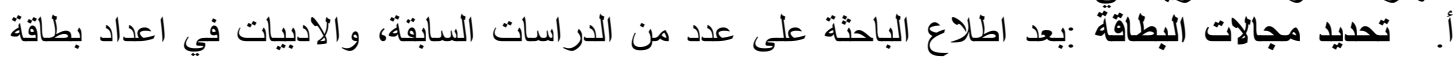

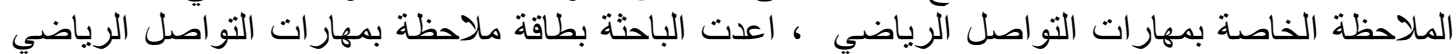

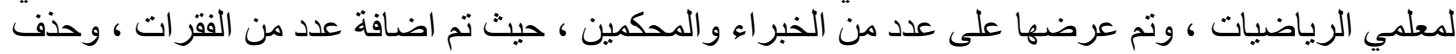

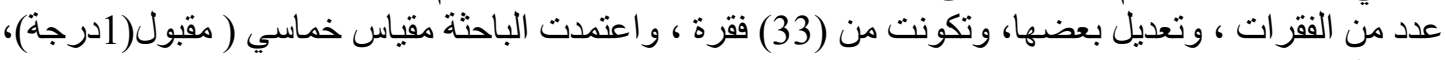

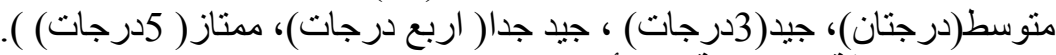

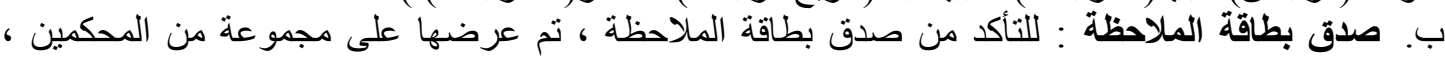

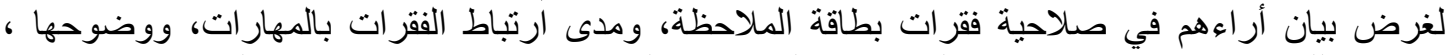

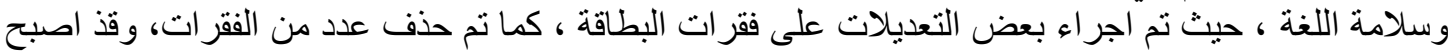

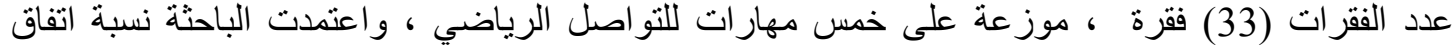

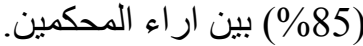
ت. ثبات بطاقة الملاحظة :للنأكد من ثبات بطاقة الملاحظة استعانة الباحثة بمدرسة2 من حملة الثهادات العليا،

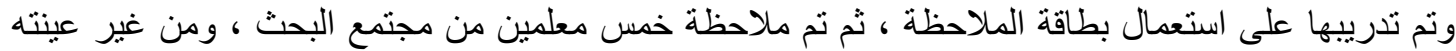

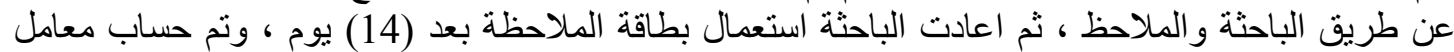

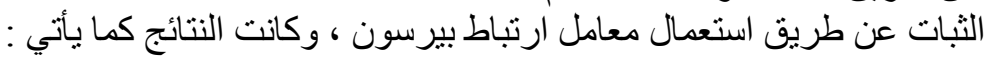

\begin{tabular}{|r|r|r|}
\hline درجة الثبات & الباحثة مع نفسهات & 1 \\
\hline 0.91 & الباحثة مع الملاحظ & 2 \\
\hline 0.89 &
\end{tabular}

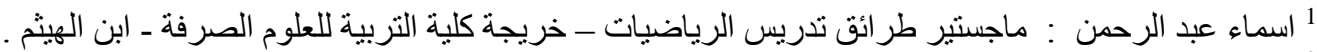

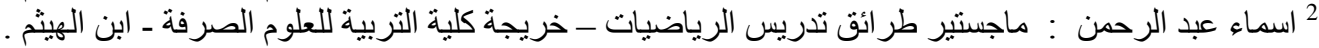




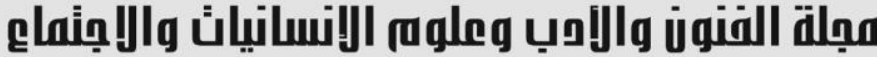

Journal of Arts, Literature, Humanities and Social Sciences www.jalhss.com

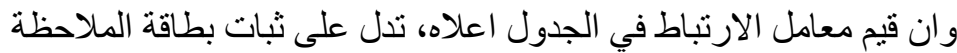

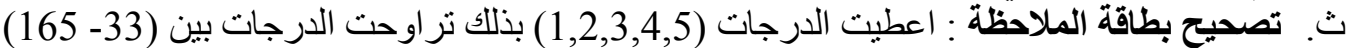
ج. تطبيق بطاقة الملاحظة :تم تطبيق بطاقة الملاحظة على معلمي ومعلمات الرياضيات ، وزيارتهم داخل الصفوف .

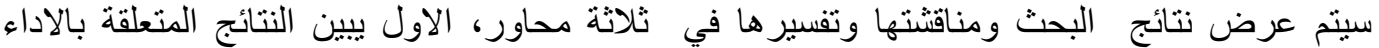

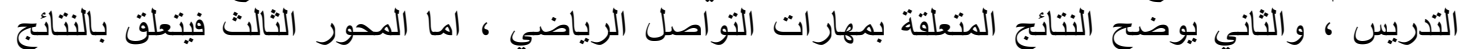

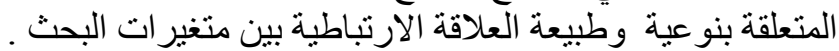

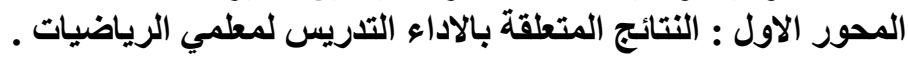

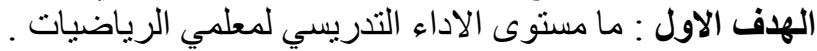

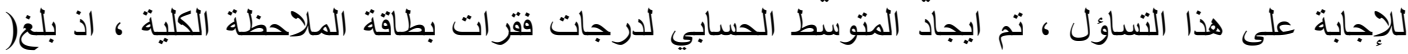

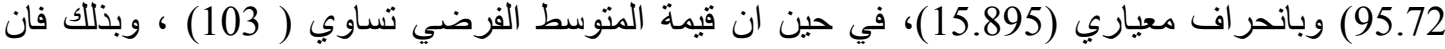

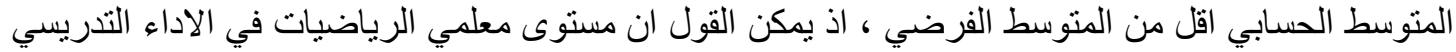

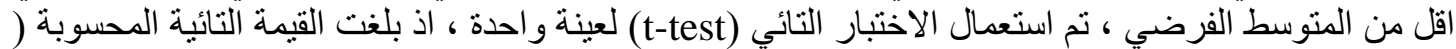

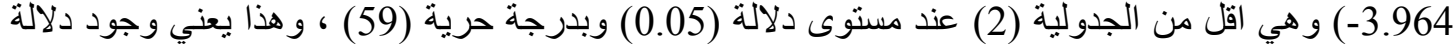

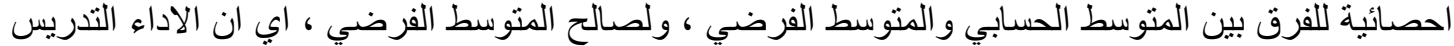
لمعلمي الرياضيات منوسط ، كما في الجدول الاتي :

\begin{tabular}{|c|c|c|c|c|c|c|c|c|}
\hline الاحصائية عند & الجدولية & المحسوبة & الحرجة & الفرضي & الالانحري اف & الحسابي & العدد & المتغير \\
\hline الفترسط & 2 & -3.964 & 59 & 103 & 15.895 & 95.72 & 60 & الاداء التدريس \\
\hline
\end{tabular}

المحور الثاني :النتائج المتعلقة بمهارات التواصل الرياضي لمعلمي الرياضيات .

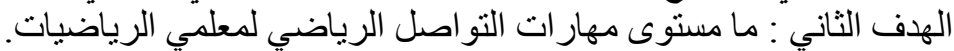

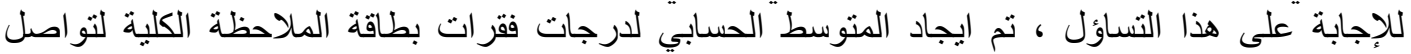

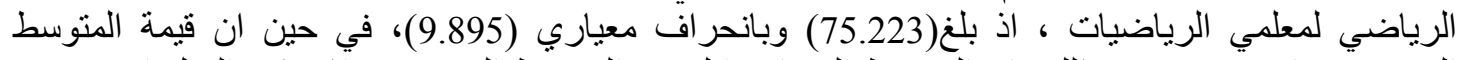

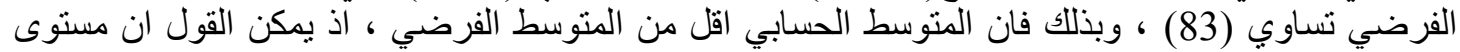

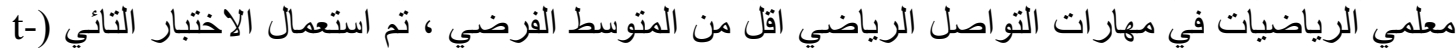

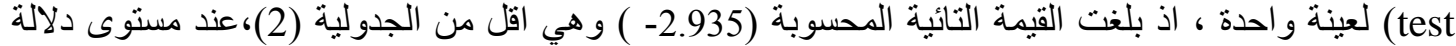

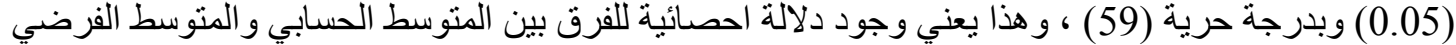
، ولصالح المنتوسط الفرضي ، ابي ان مستوى مهار ات التواصل الصل الرياضي لمعلمي الرياضيات منوسط ، كما في الريطي

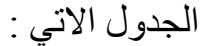

\begin{tabular}{|c|c|c|c|c|c|c|c|c|}
\hline الدلالة الاحصائية & الجدولية & المحسوبة & درجة & الفرضطي & الالحعراف & الحستوسطي & العدد & المتغير \\
\hline المتوسط الفرضي لصالح & 2 & -2.935 & 59 & 83 & 9.895 & 75.223 & 60 & التدريس \\
\hline
\end{tabular}




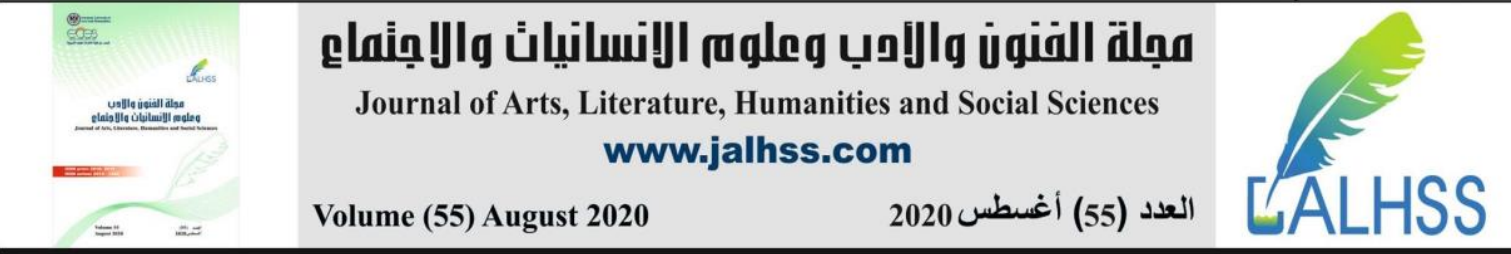

المحور الثالث: النتائج المتعلقة بنوعية وطبيعة العلاقة الارتباطية بين متغيرات البحث .

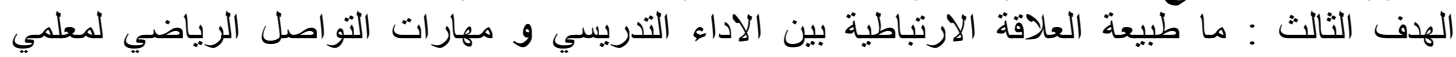

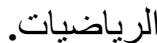

للإجابة على هذا التساؤل ، تم استعمال معامل ارتباط بيرسون ' لإيجاد العلاقة بين الاداء التنريسي لمعلمي

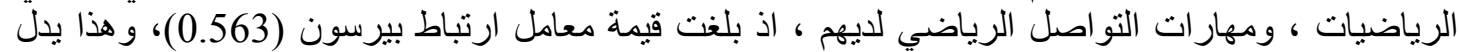

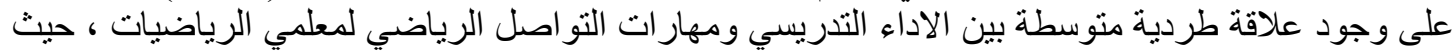

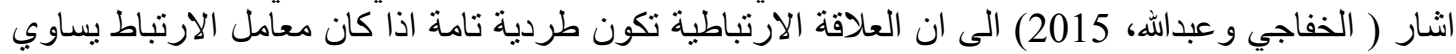

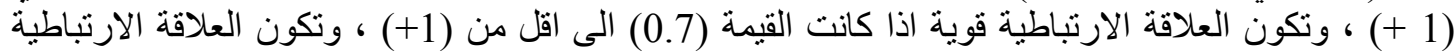

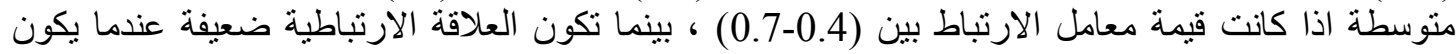

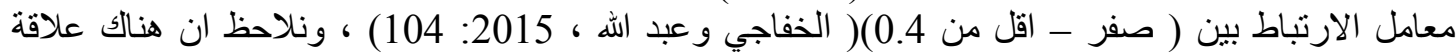

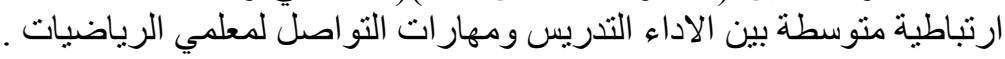

\section{تفسير النتائج : 1}

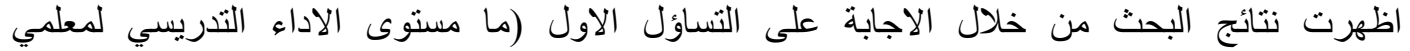

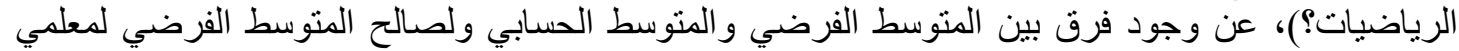

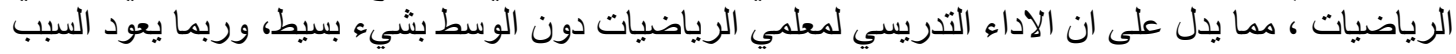

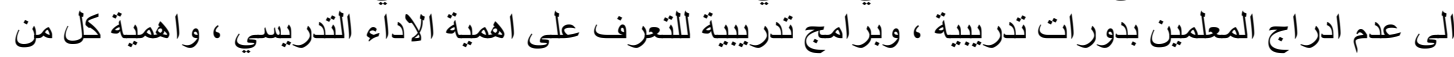
التخطيط و التنفيذ و التقويم. التمين.

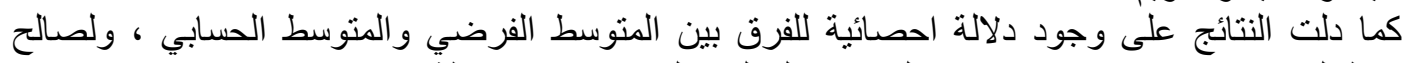

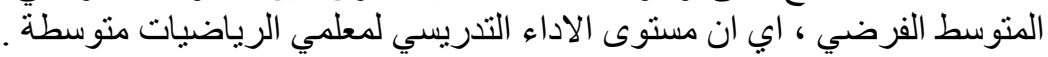

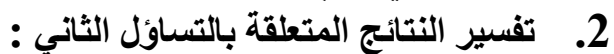

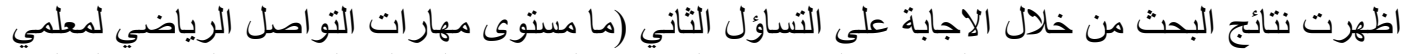

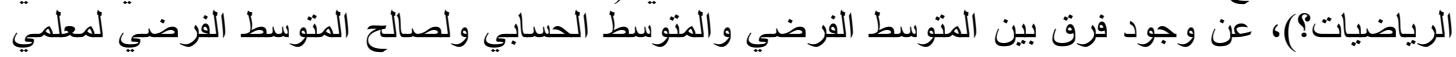

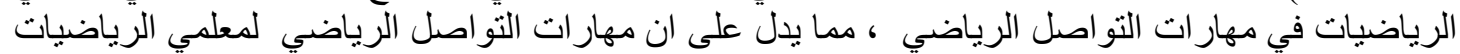

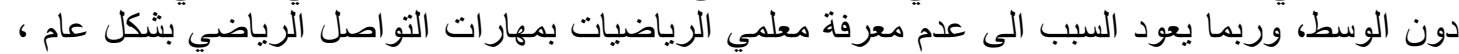

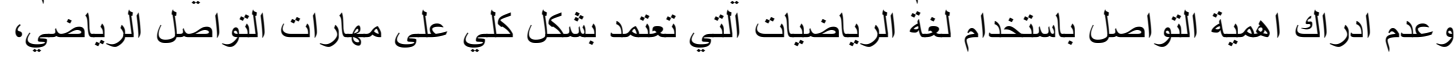

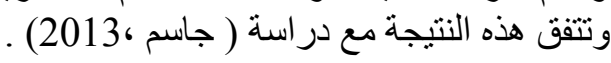

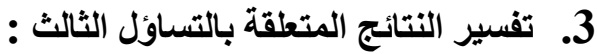

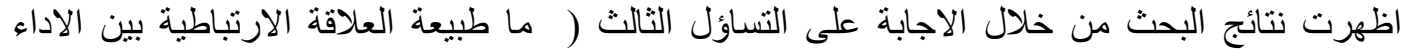

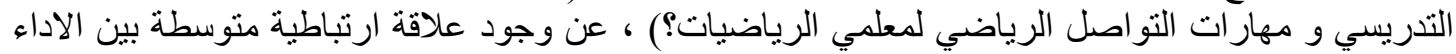

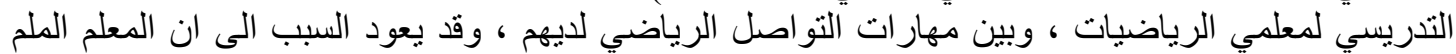

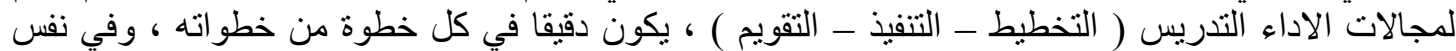

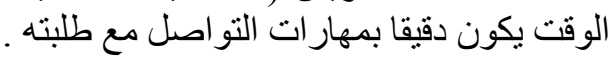

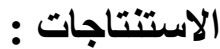
في ضوء الأتائج البحث : الحالي ، يمكن ان نستنتج ما يأتي :

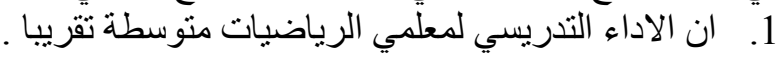

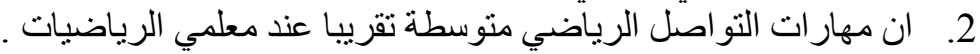

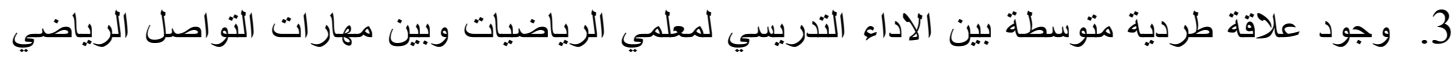




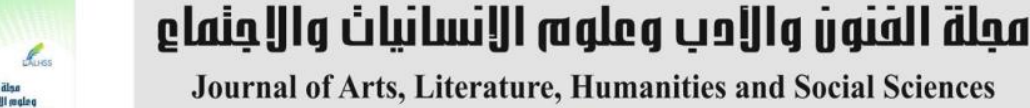

www.jalhss.com

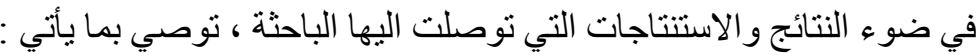

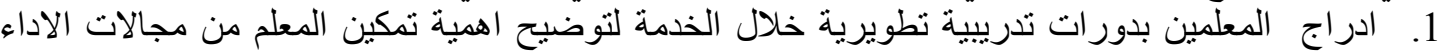

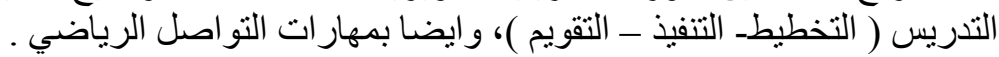

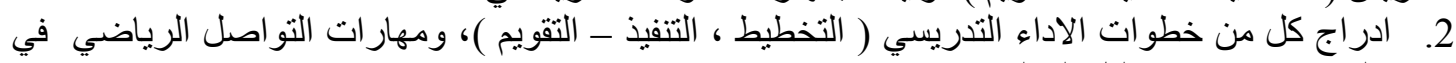

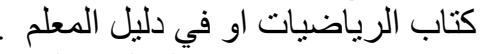

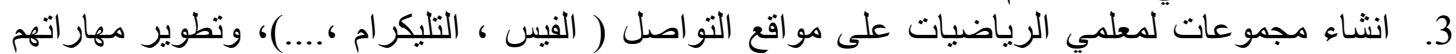
و اثراء معلوماتهم عن كل ما هو جديد عن الاداء التندريسي ومهار التئ التهات التواصل ، و وغير ها مما بطور شخصية

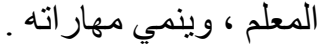

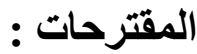

استكمالا للبحث الحالي تقتر ح الباحثة اجر اء الدر اسات الاتية : 1. بناء برنامج تدريبي في مهار التات التو اصل الرئي الرياضي لمعلمي الرياضيات وبيان اثره في اداءهم التدريسي و

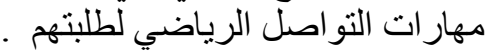
2. بناء برنامج تدريبي قائم علة الاداء التدريسي ، وبيان اثره في الاداء التدريسي لمعلمي الرياضيات وتحصيل

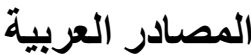

1. بدوي ،رمضان مسعد(2003 ):استر اتيجيات في تعليم وتقويم تعلم الرياضيات ، ط1 ، دار الفكر ،عمان،

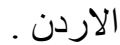

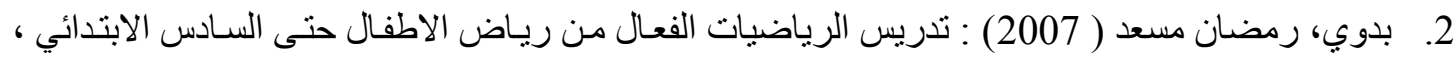

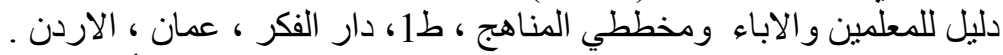

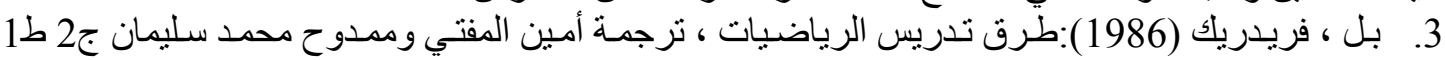

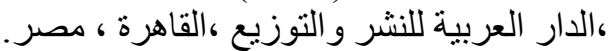

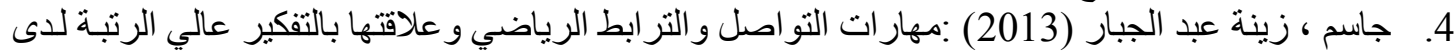

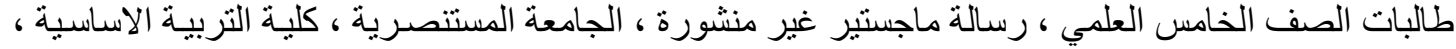

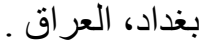
5. الجر ادي ، محمد ( 2006 ): القدرة القر ائية للمفاهيم الرياضية و علاقتها بالتحصيل لدى طلبة الصف الثامن

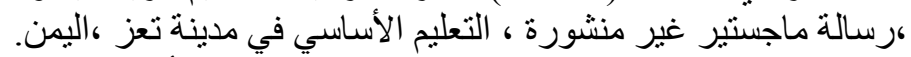

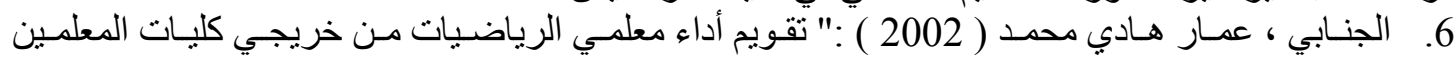

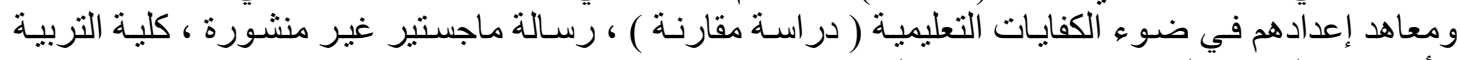

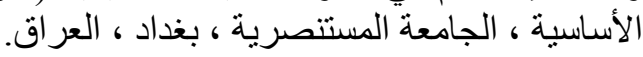

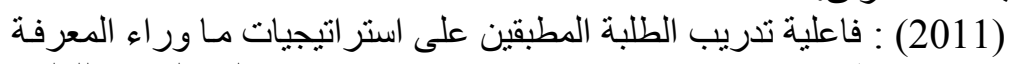

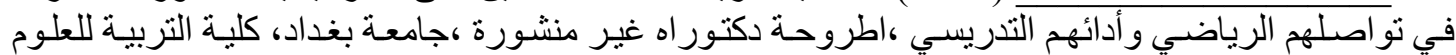

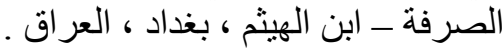

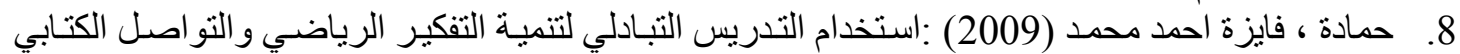
بالمرحلة الاعدادية في ضوء بايزة بعض معايير الرياضيات المدرسية ،المجلة العلمية ـ كلية التربية ، مجلد 25 ، عدد الترائ

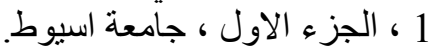

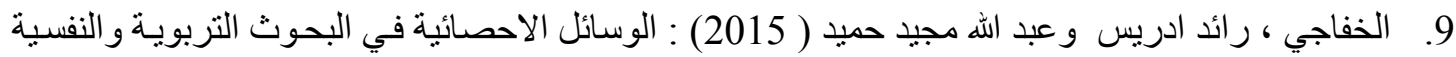

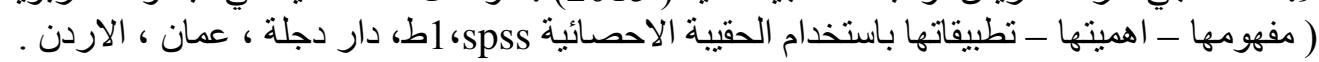

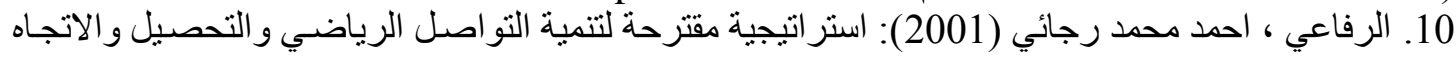

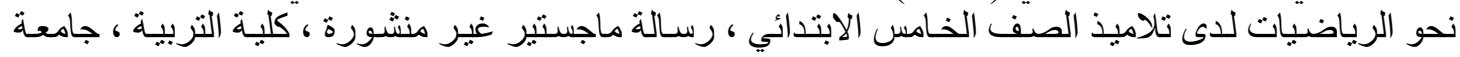




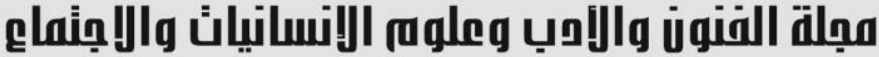

Journal of Arts, Literature, Humanities and Social Sciences www.jalhss.com

11. السعدي ، رفاه عزيز كريم(2009): بناء برنـامج تدريسي لمهار ات التواصل الرياضي للطلبة / المطبقين وأثره في مهار ات التو اصل الرياضي لطلبتهم، اطروحة دكتور اه غير منشورة ،جامعة بغداد، كلية التربية للعلوم

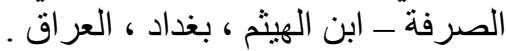

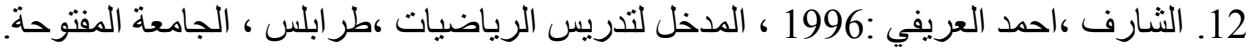

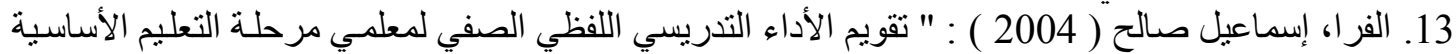

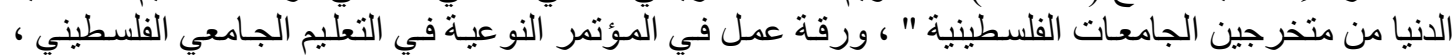

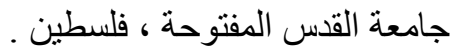
14. فريمـان، جون الفونة (1998):التربيـة الأساسية النخبـة ( ترجمـة صـالحة سنقر) ،المركز العربي للتعريب

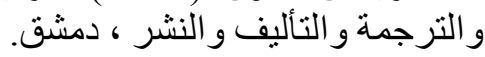

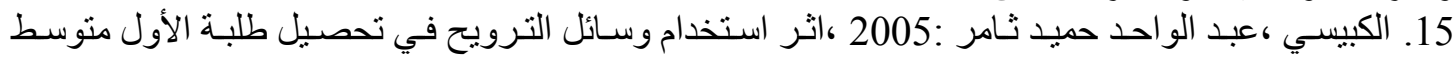

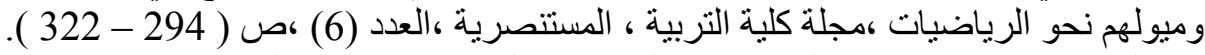

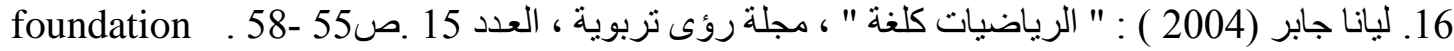
.org \pdf1677.pdfwww.qattan

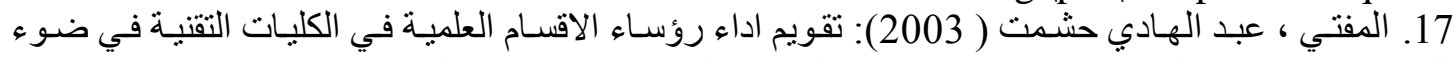

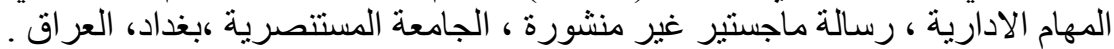
18. المفتي ، محمد أمين ( 1982 ) : سلوك التدريس ، مؤسسة الخليج العربي ، مطبعة النهضة ، القئة القاهرة . 


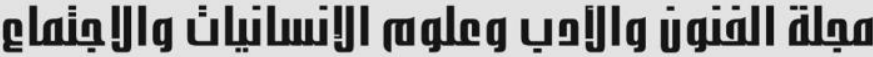 \\ Journal of Arts, Literature, Humanities and Social Sciences www.jalhss.com

\section{References}

1. Badawi, Ramadan Masaad (2003): Strategies in Teaching and Evaluating Mathematics Learning, 1st Floor, Dar Al-Fikr, Amman, Jordan.

2. Badawi, Ramadan Masaad (2007): Effective Mathematics Teaching from Kindergarten to Sixth Primary, Manual for Teachers, Parents, and Curriculum Planners, 1st Floor, Dar Al-Fikr, Amman, Jordan.

3. Rather, Frederick (1986): Methods of Teaching Mathematics, translated by Amin Al-Mufti and Mamdouh Muhammad Suleiman, Part 2, 1st floor, The Arab House for Publishing and Distribution, Cairo, Egypt.

4. Jassem, Zina Abdul-Jabbar (2013): Communication skills and mathematical interconnection and its relationship to high-level thinking among fifth-grade students in science, unpublished Master Thesis, Al-Mustansiriya University, College of Basic Education, Baghdad, Iraq.

5. Al-Jaradi, Muhammad (2006): The Reading Capacity of Mathematical Concepts and their Relationship to Achievement among Eighth Grade Students, Unpublished Master Thesis, Basic Education in Taiz City, Yemen.

6. Al-Janabi, Ammar Hadi Muhammad (2002): "Evaluating the performance of mathematics teachers from graduates of teacher colleges and institutes of preparing them in the light of educational competencies (a comparative study), unpublished Master Thesis, College of Basic Education, Al-Mustansiriya University, Baghdad, Iraq.

7. _ (2011): Effectiveness of training students applying to metacognitive strategies in their mathematical communication and teaching performance, unpublished doctoral thesis, University of Baghdad, College of Education for Pure Sciences - Ibn AlHaytham, Baghdad, Iraq.

8. Hamada, Fayza Ahmed Mohamed (2009): the use of reciprocal teaching to develop mathematical thinking and written communication in the intermediate stage in light of some school mathematics standards, the scientific journal - College of Education, volume 25, number 1, first part, Assiut University.

9. Al-Khafaji, Raed Idris and Abdullah Majeed Hameed (2015): Statistical methods in educational and psychological research (its concept - its importance - its applications using the statistical bag spss, 1st edition, Dar Degla, Amman, Jordan.

10. Al-Rifai, Ahmad Muhammad Rajaei (2001): A proposed strategy for developing mathematical communication, achievement and the trend towards mathematics among fifth-grade primary students, unpublished master's thesis, Faculty of Education, Tanta University, Egypt.

11. Al-Saadi, The Welfare of Aziz Karim (2009): Building a teaching program for mathematical communication skills for students / applicants and its effect on mathematical communication skills for their students, unpublished doctoral thesis, University of Baghdad, College of Education for Pure Sciences - Ibn Al-Haytham, Baghdad, Iraq.

12. Al-Sharf, Ahmed Al-Areifi: 1996, entrance to teaching mathematics, Tripoli, The Open University. 


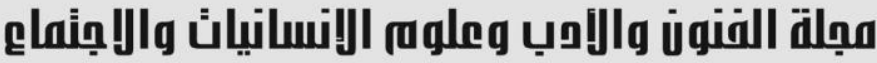 \\ Journal of Arts, Literature, Humanities and Social Sciences www.jalhss.com

13. Al-Farra, Ismail Saleh (2004): "Evaluating the verbal, verbal teaching performance of lower basic education teachers graduating from Palestinian universities", a working paper at the Specific Conference in Palestinian University Education, Al-Quds Open University, Palestine.

14. Freeman, John (1998): Elite Basic Education (validated translation), The Arab Center for Arabization, Translation, and Publication, Damascus.

15. Al-Kubaisi, Abdul Wahid Hameed Thamer: 2005, The effect of using recreational methods in achieving the first average students and their tendencies towards mathematics, Journal of the College of Education, Al-Mustansiriya, No. (6), pp. (294 - 322).

16. Liana Jaber (2004): "Mathematics as a Language," Journal of Educational Insights, No. 15, pp. 55-58. foundation .org \pdf $\backslash$ 677.pdfwww.qattan

17. Mufti, Abdel-Hadi Heshmat (2003): Evaluating the performance of heads of scientific departments in technical colleges in the light of administrative tasks, unpublished Master Thesis, Al-Mustansiriya University, Baghdad, Iraq.

18. Mufti, Muhammad Amin (1982): Teaching behavior, Arab Gulf Foundation, AlNahda Press, Cairo.

19. Baroody, a.j. (1998), problem solving, reasoning, and communicating k-8 : helping children think mathematically, macmillan publishing company, newyork.

20. Cantlon , d. (1998), mathematics power, teaching children mathematics , 5 (2), p. $108-112$.

21. Morgan, C.( 1999) :Communicating Mathematically , In Wilder ,S. J. ;Wilder , Prim ,D. AND Wes well ,J. (Eds), Learning to teach Mathematics in the Secondary School, Rout ledge , London, p.129- 143.

22. National Council Of Teacher's Of Mathematics (NCTM) ,URL,(1989):NCTM "Curriculum and evaluation standards for school mathematics", NCTM.

23. Pape,S.j\&,F Tchoshanov , M.A (2001) . The Role of Representation (s) in Developing Mathematical Understanding . Theory Into Practice ,40 (2), 118.

24. Thompson, Denicss R.\& Michale F .Chappell (2007): ,Communication and Represntation as elements in Mathematical Literacy ,J.Reading and Writing Quarterly ,23, p. 179- 196. 